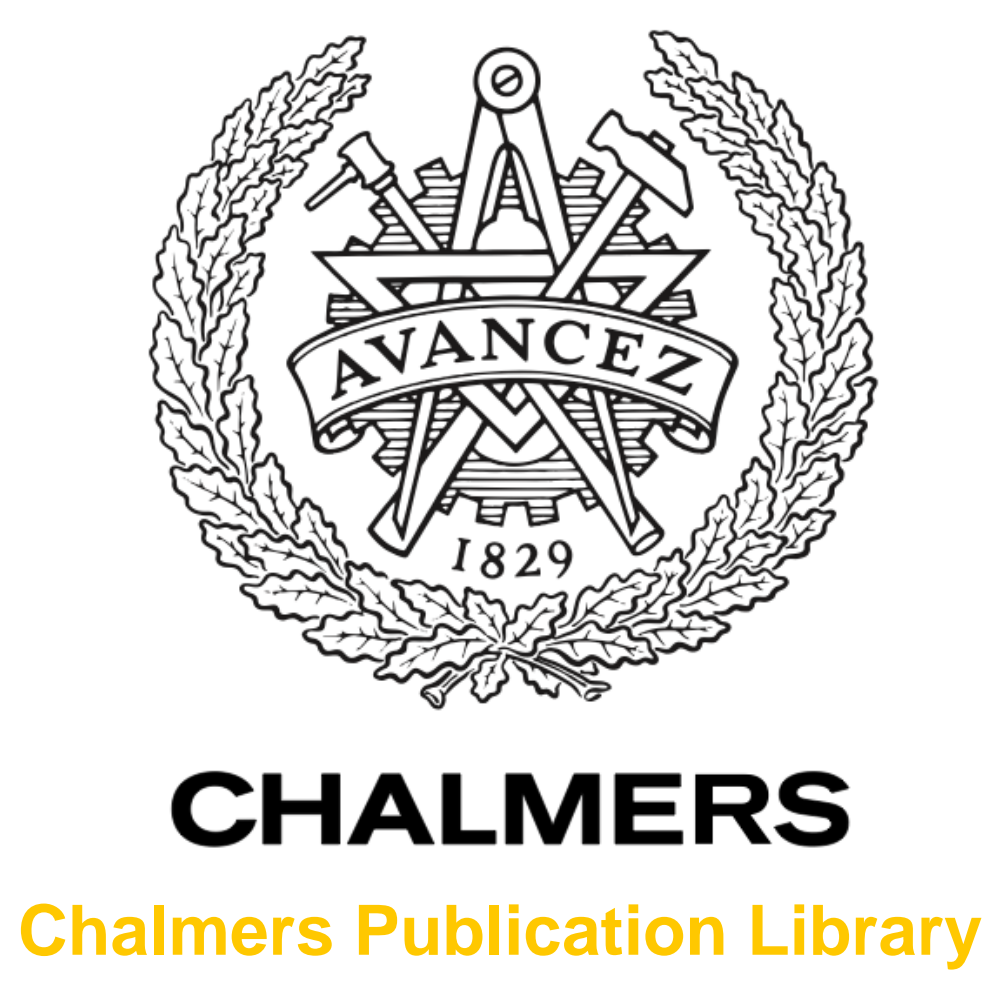

\title{
BorealScat: A Tower-Based Tomographic and Polarimetric Radar Experiment in the Boreal Forest at P- and L-Band
}

This document has been downloaded from Chalmers Publication Library (CPL). It is the author's version of a work that was accepted for publication in:

Proceedings of IEEE International Geoscience and Remote Sensing Symposium

Citation for the published paper:

Monteith, A. ; Soja, M. ; Ulander, L. et al. (2016) "BorealScat: A Tower-Based Tomographic and Polarimetric Radar Experiment in the Boreal Forest at P- and L-Band". Proceedings of IEEE International Geoscience and Remote Sensing Symposium pp. 7458 - 7461.

Downloaded from: http://publications.lib.chalmers.se/publication/245824

Notice: Changes introduced as a result of publishing processes such as copy-editing and formatting may not be reflected in this document. For a definitive version of this work, please refer to the published source. Please note that access to the published version might require a subscription.

Chalmers Publication Library (CPL) offers the possibility of retrieving research publications produced at Chalmers University of Technology. It covers all types of publications: articles, dissertations, licentiate theses, masters theses, conference papers, reports etc. Since 2006 it is the official tool for Chalmers official publication statistics. To ensure that Chalmers research results are disseminated as widely as possible, an Open Access Policy has been adopted.

The CPL service is administrated and maintained by Chalmers Library. 


\title{
BOREALSCAT: A TOWER-BASED TOMOGRAPHIC AND POLARIMETRIC RADAR EXPERIMENT IN THE BOREAL FOREST AT P-, L- AND C-BAND
}

\author{
Albert R. Monteith, Maciej J. Soja, Lars M. H. Ulander, Leif E. B. Eriksson \\ Chalmers University of Technology, Gothenburg, Sweden
}

\begin{abstract}
This paper describes BorealScat, a tower-based radar campaign for acquiring multitemporal polarimetric, tomographic and Doppler radar measurements at P-, L- and C-band over a hemi-boreal forest site in Remningstorp, Sweden. The facility consists of a 50-m high tower equipped with a radar system including an array of 30 antennas. The site will also be equipped with meteorological instruments and moisture sensors. The aim of the experiment is the temporal survey of radar signatures over time scales ranging from sub-seconds to years in varying environmental conditions. This experiment will provide fundamental information about the electromagnetic scattering mechanisms in boreal forests at P-, L- and C-band.
\end{abstract}

Index Terms - Polarimetry, SAR tomography, BIOMASS, SAOCOM-CS, ground-based radar, boreal forest, long time series

\section{INTRODUCTION}

Forests around the globe play a major role in climate regulation through the sequestration of carbon in forest biomass [1]. The global forest carbon stock has therefore been identified as a much needed parameter for climate modelling and prediction [2]. To fulfil this need, the BIOMASS satellite was selected for the $7^{\text {th }}$ Earth Explorer Mission by the European Space Agency (ESA) in May 2013 [3]. This will be the first ever P-band (435 MHz) synthetic aperture radar (SAR) satellite and will allow for the estimation and mapping of above-ground forest biomass. During the first nine months of the mission, BIOMASS will operate in a repeat-pass tomographic SAR (TomoSAR) mode, providing vertical backscattering profiles, which requires several acquisitions over the same site from slightly different incidence angles. These acquisitions are expected to have a revisit time of three days. Thereafter, the satellite will operate in a polarimetric and interferometric SAR (PolInSAR) mode.

Temporal changes in forests occurring within and between acquisitions can have severely detrimental effects on the measurements [2]. It is therefore of interest to study the temporal decorrelation in forests in order to better understand the scattering mechanisms as they vary over time.
The airborne and tower-based radar campaigns TropiSAR (2009) and TropiScat (2011-2014), respectively, have studied the temporal decorrelation in a tropical forest site in Paracou, French Guiana $[4,5]$. These studies provided valuable information about the scattering mechanisms and suitable acquisition times for BIOMASS in tropical forests. However, these results cannot be extrapolated to boreal forests due to the differences in tree species, seasonal changes and more dynamic environmental conditions at higher latitudes. Strong winds can cause Doppler shifts during the integration time due to a moving forest canopy. Moisture in forested areas also affect electromagnetic scattering, introducing a bias in the estimated biomass. It is therefore important to better understand these effects and improve current forest parameter estimation models for their mitigation.

Unfortunately, due to International Telecommunication Union regulations, BIOMASS acquisitions over Europe and North America will be limited. ESA is therefore investigating the implementation of an L-band (1270 MHz) SAR tomography mission, SAOCOM-CS. Forest monitoring is also one of the aims of the Sentinel-1 mission operating at C-band (5405 $\mathrm{MHz})$. Therefore, the influence of temporal changes, seasons and weather on radar measurements in boreal forests should also be studied at L- and C-band.

In order to study the influence of temporal changes in boreal forests on the electromagnetic scattering at P-, L- and C-band, a tower-based radar campaign, BorealScat, has been initiated in an experimental hemi-boreal forest site in Remningstorp, Sweden [6]. The dedicated 50-m high tower will be equipped with an array of 30 antennas connected to a 20-port vector network analyzer (VNA) allowing for Doppler, tomographic and fully polarimetric radar measurements. The site will also be equipped with meteorological instruments, moisture sensors and web cameras. This information will allow for the development of a better understanding of scattering mechanisms in boreal forests at P-, L- and C-band and how they vary with seasons and environmental conditions.

This aim of this paper is to describe the forest site, experimental setup, acquisition method, calibration and design of the tomographic antenna array for the BorealScat campaign.

@ 2016 IEEE. Personal use of this material is permitted. Permission from IEEE must be obtained for all other uses, in any current or future media, including reprinting/republishing this material for advertising or promotional purposes, creating new collective works, for resale or redistribution to servers or lists, or reuse of any copyrighted component of this work in other works. 


\section{SITE DESCRIPTION}

Remningstorp is an experimental hemi-boreal forest site located in southern Sweden, consisting of approximately 1200 ha of productive forest land. The BorealScat experiment (located at $58^{\circ} 27^{\prime} 5^{\prime \prime} \mathrm{N}, 13^{\circ} 37^{\prime} 35^{\prime \prime} \mathrm{E}$ ) will observe a homogeneous forest stand with a fairly flat topography and dominated by Norway spruce (Picea abies L.). The height of trees within the stand varies from $25 \mathrm{~m}$ to $27 \mathrm{~m}$.

\section{EXPERIMENTAL SETUP}

\subsection{System overview}

The main hardware components of the radar system are a VNA, a switching matrix, an antenna array and a computer, which automatically conducts the measurement sequences. All components are connected to a local network which can be accessed remotely through the Internet via a $4 \mathrm{G}$ mobile broadband modem. Measurement data will be automatically uploaded to a remote server via this $4 \mathrm{G}$ connection. The VNA, switching matrix and computer will be located in a climate-controlled equipment hut at the base of the tower. The array of 30 antennas at the top of the tower will be connected to the switching matrix using 60-m low-loss cables with a one-way attenuation of approximately $2.8 \mathrm{~dB}$ at P-band, $5 \mathrm{~dB}$ at L-band and $12 \mathrm{~dB}$ at C-band. The purpose of the switching matrix is to route the VNA ports between the antennas and a single reference cable, allowing for an internal calibration of the VNA at regular intervals.

\subsection{Antennas}

The antennas must be capable of withstanding severe environmental conditions like ice deposits and winds up to $150 \mathrm{~km} / \mathrm{h}$. For these reasons, 20 wideband log-periodic antennas (Rhode \& Schwarz HL040E model) were selected for P- and L-band measurements. These antennas feature a protective moistureisolating radome and a sturdy mount that can withstand winds up to $180 \mathrm{~km} / \mathrm{h}$ with ice deposits. The $3-\mathrm{dB}$ beamwidths in the E- and $\mathrm{H}$-plane are $68^{\circ}$ and $114^{\circ}$ respectively at P-band and $60^{\circ}$ and $98^{\circ}$ respectively at L-band. For C-band, 10 dualpolarized flat panel antennas will be used. These antennas feature a narrower beamwidth of $20^{\circ}$ and much higher gain of $18 \mathrm{dBi}$ which is necessary for compensating for system losses at C-band.

\subsection{Vector network analyzer}

The purpose of the VNA is to generate the transmitted stepped-frequency continuous wave (SFCW) signal and measure the backscattered signal. A 20-port VNA (Rohde \& Schwarz ZNBT8 model) was selected to perform simultaneous measurements, minimizing the need for mechanical switching during measurements. This significantly reduces the measurement acquisition time and extends the functional lifetime of the mechanical switching matrix.

\subsection{Calibration}

The system features two calibration procedures. An internal calibration will be performed using the reference cable connected to the switching matrix, all located within the climatecontrolled equipment hut. This calibration procedure will compensate for systematic errors contributed to by the VNA, but will not affect the systematic errors contributed to by the low-loss cables and antennas external to the equipment hut. A trihedral corner reflector will therefore be permanently installed in the forest in direct line-of-site of the antennas, allowing for an external calibration.

\section{TOMOGRAPHIC ANTENNA ARRAY DESIGN}

The purpose of the antenna array is to allow the fully polarimetric reconstruction of vertical backscattering profiles of the observed forest. This requires a particular array configuration in order to achieve a suitable resolution and an unambiguous height. For a vertical linear array of $N$ equidistantly spaced antennas with spacing $\Delta z$, the vertical resolution $\rho_{z}$ and height of ambiguity $z_{\mathrm{amb}}$ at broadside are calculated as

$$
\begin{aligned}
\rho_{z} & =\frac{\lambda}{2 A_{z}} R \\
z_{\mathrm{amb}} & =\frac{\lambda}{2 \Delta z} R
\end{aligned}
$$

where $\lambda$ is the wavelength, $R$ the radial distance from the array and $A_{z}=(N-1) \Delta z$ is the tomographic aperture [7]. In order to have a sufficiently large height of ambiguity, the required spacing between the antennas must be smaller than what the physical dimensions of the antennas allow. To overcome this problem, a similar array design approach to that of TropiScat was used [8]. This tomographic array design method uses the concept of a virtual array, which is an array that meets the requirements of a particular resolution and unambiguous height. The real array is then configured to excite the same wavenumbers as the virtual array, while having the antennas spaced sufficiently far apart to avoid physical obstructions and significant mutual coupling.

The $20 \mathrm{~L} / \mathrm{P}$-band antennas are therefore mounted in four columns with 5 antennas each, two columns for transmitting and two for receiving, with one column vertically polarized and the other horizontally polarized in each case. The array configuration used in the TropiScat experiment was modified to meet the additional requirement that the BorealScat system must operate at L-band, which according to (2) results in a lower height of ambiguity. BorealScat antennas also feature a wider beamwidth, enhancing the unwanted backscatter from the tower. These problems were overcome by firstly tilting the antenna array downwards and secondly widening the antenna 
spacings to minimize mutual coupling. The array tilt has the effect of placing the observed forest at broadside to the center of the elevation aperture, where the unambiguous height is at a maximum, allowing the reconstruction of unambiguous tomographic forest profiles up to L-band. It also has the effect of placing the tower at an angle to the array where the resolution is finite, decreasing the smear in the backscattering profile that would otherwise appear due to the tower.

In order to find the best antenna spacings and tilt angle (complement of the look angle), the tomographic profiles for multiple antenna spacings and tilt angles were simulated and evaluated in terms of resolution and height of ambiguity. The Born approximation was used for the forward simulation, taking the far-field antenna radiation patterns into account. The tomographic profiles were constructed through coherent focusing [9]. Point scatterers were used to model the presence of the tower, ground and forest. The forest point scatterers were randomly distributed up to a height of $15 \mathrm{~m}$, which is the maximum expected height of the scattering center for the stand of interest at P- and L-band. Figures $1 \mathrm{a}$ and $\mathrm{b}$ show the resulting profiles at $\mathrm{P}$ - and L-bands for the selected array configuration (Fig. 2a) and a look angle of $75^{\circ}$. The lowest significant vertical ambiguities appear as artefacts higher than $30 \mathrm{~m}$ which is above the physical height of the canopy and is therefore not a concern. The effects from the tower are visible but do not interfere with the forest response. The resulting height resolution at a range of $40 \mathrm{~m}$ at $\mathrm{P}$ - and L-band are approximately $4.7 \mathrm{~m}$ and $1.6 \mathrm{~m}$ respectively, whereas the height of ambiguity is $103 \mathrm{~m}$ and $35 \mathrm{~m}$ respectively.

This array is however not useful at C-band since the virtual array spacings $\Delta z$ are too large, resulting in an ambiguous backscattering profile. Therefore, smaller antennas were used and configured with closer spacings as shown in Figure $2 \mathrm{~b}$. Figure $1 \mathrm{c}$ shows the simulated tomographic profile at $\mathrm{C}$-band, with point scatterers up to $30 \mathrm{~m}$. The C-band array is tilted for a look angle of $40^{\circ}$ in order to direct the narrow main lobe of the antenna at a similar look angle to that of SAR satellites. Although the ambiguities are visible at a ground range of $0 \mathrm{~m}$ and height of $30-50 \mathrm{~m}$, they are well outside the beamwidth of the antennas and are therefore not a problem. The resulting height resolution at a range of $40 \mathrm{~m}$ at C-band is approximately $1.6 \mathrm{~m}$, whereas the heigh of ambiguity is 26.6 $\mathrm{m}$.

\section{DATA ACQUISITION METHOD}

A single measurement sequence will include an external calibration and transmission parameter measurement for all Tx-Rx antenna combinations. The frequency step $\delta f$ of the SFCW signal determines the unambiguous range $R_{u}$ according to $R_{u}=c /(2 \delta f)$ and was selected to be $0.5 \mathrm{MHz}$, giving an unambiguous range of $300 \mathrm{~m}$. The range resolution is determined by the bandwidth, which was not yet decided upon at the time of writing due to a pending spectrum license application.

Temporal decorrelation will also be studied by operating the VNA in continuous wave mode, allowing the measurement of the Doppler shifts caused by a wind-blown canopy.

\section{REFERENCES}

[1] K. Trumper, M. Bertzky, B. Dickson, G. van der Heijden, M. Jenkins, and P. Manning, The Natural Fix?: The Role of Ecosystems in Climate Mitigation: a UNEP Rapid Response Assessment, UNEP/Earthprint, 2009.

[2] T. Le Toan, S. Quegan, M. W. J. Davidson, et al., "The BIOMASS mission: Mapping global forest biomass to better understand the terrestrial carbon cycle," Remote Sensing of Environment, vol. 115, no. 11, pp. 2850-2860, 2011.

[3] ESA (2012), Report for Mission Selection: BIOMASS, ESA SP-1324/1 (3 volume series), European Space Agency, Noordwijk, The Netherlands.

[4] P. C. Dubois-Fernandez, T. Le Toan, S: Daniel, H. Oriot, J. Chave, L. Blanc, L. Villard, M. W. J. Davidson, and M. Petit, "The Tropisar airborne campaign in French Guiana: Objectives, description, and observed temporal behavior of the backscatter signal," Geoscience and Remote Sensing, IEEE Transactions on, vol. 50, no. 8, pp. 3228-3241, 2012.

[5] C. Albinet, P. Borderies, T. Koleck, F. Rocca, S. Tebaldini, L. Villard, T. Le Toan, A. Hamadi, and D. Minh, "Tropiscat: A ground based polarimetric scatterometer experiment in tropical forests," Selected Topics in Applied Earth Observations and Remote Sensing, IEEE Journal of, vol. 5, no. 3, pp. 1060-1066, 2012.

[6] M.H. Ulander, M.J. Soja, A.R. Monteith, L. E. B. Eriksson, and J. E. S. Fransson, "BorealScat: A tower experiment for understanding temporal changes in $\mathrm{P}$ - and L-band backscattering from a boreal forest," in Living Planet Symposium, 2016.

[7] A. Reigber and A. Moreira, "First demonstration of airborne SAR tomography using multibaseline L-band data," Geoscience and Remote Sensing, IEEE Transactions on, vol. 38, no. 5, pp. 2142-2152, 2000.

[8] H. T. M. Dinh, S. Tebaldini, F. Rocca, T. Koleck, P. Borderies, C. Albinet, L. Villard, A. Hamadi, and T. Le Toan, "Ground-based array for tomographic imaging of the tropical forest in P-band," Geoscience and Remote Sensing, IEEE Transactions on, vol. 51, no. 8, pp. 4460-4472, 2013.

[9] M. Cheney and B. Borden, "Fundamentals of radar imaging," CBMS-NSF Regional Conference Series in Applied Mathematics, , no. 79, pp. xxi-136, 2009. 


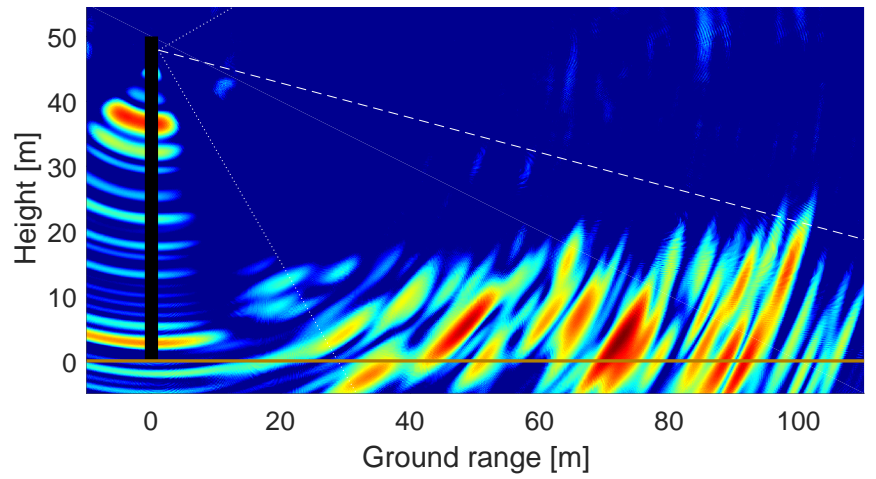

(a) P-band $\left(f_{c}=435 \mathrm{MHz}, \mathrm{B}=100 \mathrm{MHz}, \theta_{i n c}=75^{\circ}\right)$

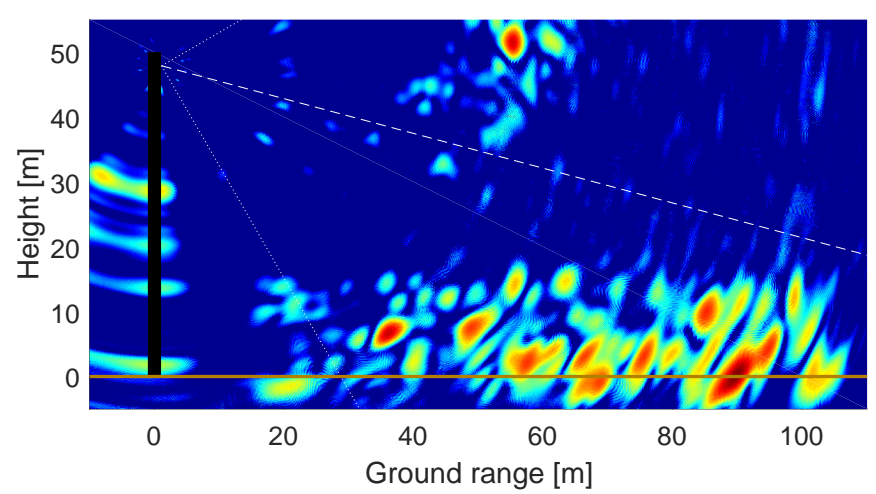

(b) L-band ( $\left.f_{c}=1270 \mathrm{MHz}, \mathrm{B}=100 \mathrm{MHz}, \theta_{i n c}=75^{\circ}\right)$

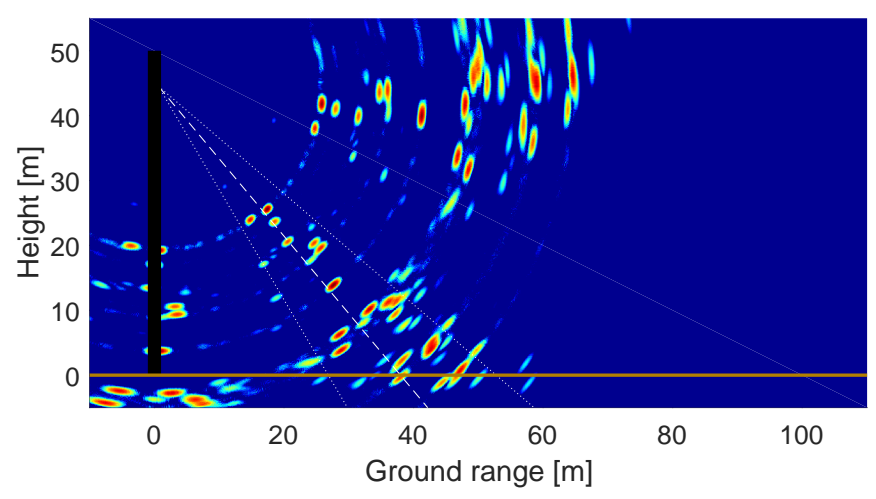

(c) C-band ( $\left.f_{c}=5400 \mathrm{MHz}, \mathrm{B}=300 \mathrm{MHz}, \theta_{i n c}=40^{\circ}\right)$

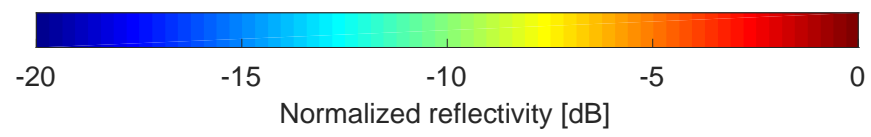

Fig. 1. Simulated tomographic profiles for the HH configuration. The black line indicates the tower and the brown line is at ground level. The white dotted lines indicate the line of sight and antenna beamwidths. $f_{c}=$ center frequency, $\mathrm{B}=$ bandwidth and $\theta_{i n c}=$ angle of incidence.

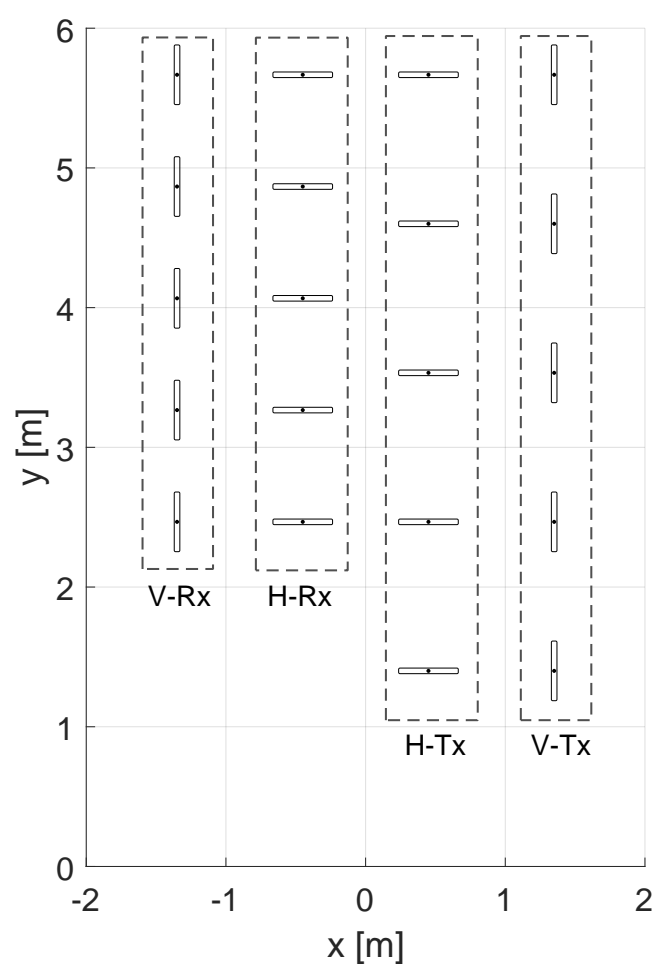

(a) P/L-band array

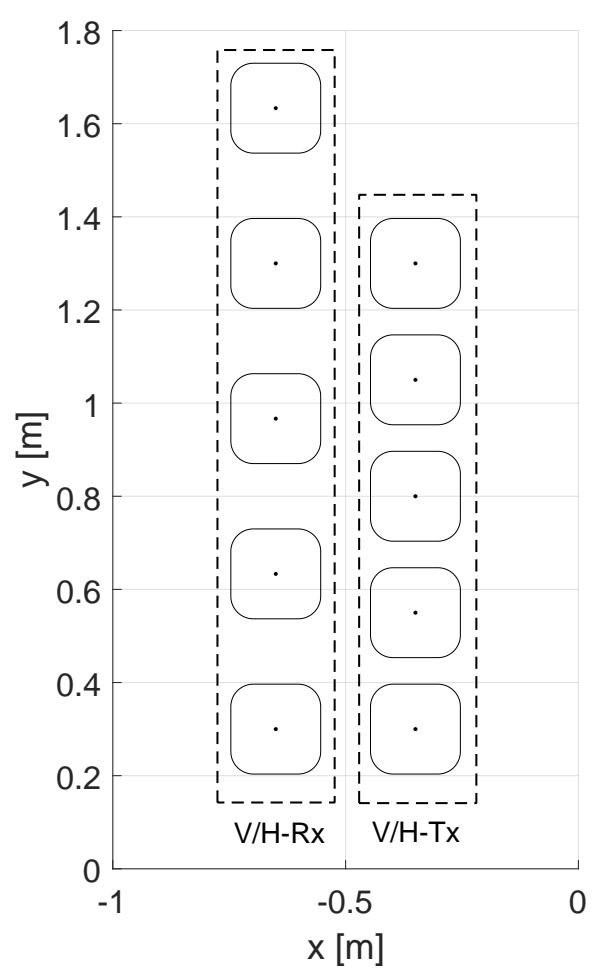

(b) C-band array

Fig. 2. Diagram of the antenna arrays, viewed from the front, in the direction normal to their supporting frames. The supporting hinge on which the array rests is at $y=0 \mathrm{~m}$. 